\title{
Public Outcomes of Publicly Funded Socio-Technical Projects
}

\author{
Reflections on Empowerment, Participation, and Researcher Responsibility \\ Peter Lyle \\ peter.lyle@cs.au.dk \\ Aarhus University \\ Denmark \\ Gopinaath Kannabiran \\ gopinaath@cs.au.dk \\ Aarhus University \\ Denmark
}

\begin{abstract}
In this short essay, we present our reflections on public outcomes of publicly funded socio-technical projects in relevance to discussions on empowerment, participation, and researcher responsibility in the field of Human Computer Interaction (HCI). Our work offers a reflective analysis and raises critical questions for further communal discussion about the life of research projects when the funding ends. When a publicly funded research project for empowering users comes to an end, how do we as HCI researchers measure the social impact of our interventions? What are the public outcomes and what are our responsibilities after we leave the field? To address these questions, first, we introduce two publicly funded socio-technical projects, situate our work with respect to current discourse on empowering users in HCI, present findings and insights based on our analysis of the projects, and conclude with a set of questions that are intended to further communal discussion.
\end{abstract}

\section{CCS CONCEPTS}

- Human-centered computing $\rightarrow$ Collaborative and social computing; • Social and professional topics $\rightarrow$ Professional topics.

\section{KEYWORDS}

empowerment, power, researcher responsibility

\section{ACM Reference Format:}

Peter Lyle and Gopinaath Kannabiran. 2019. Public Outcomes of Publicly Funded Socio-Technical Projects: Reflections on Empowerment, Participation, and Researcher Responsibility. In Proceedings of the Halfway to the Future Symposium 2019 (HTTF 2019), November 19-20, 2019, Nottingham, United Kingdom. ACM, New York, NY, USA, 3 pages. https://doi.org/10.1145/ 3363384.3363480

\section{INTRODUCTION}

We present our thoughts and contribute to the discourse on the level of publicly visible outcomes (such as documents or ICT systems) of publicly funded socio-technical research projects, with regard to what it means to those a project intends to serve. We do this, referring to work on empowerment within HCI, looking at a specific case of a European funded Participatory Design project called PIE News/Commonfare (hereafter Commonfare), in which Peter (author) was involved as a postdoc design researcher. As both authors here and now, however, the perspective of empowerment is of particular interest as part of our involvement in a different European funded project - Common Interactive Objects (hereafter CIO).

HTTF 2019, November 19-20, 2019, Nottingham, United Kingdom 2019. ACM ISBN 978-1-4503-7203-9/19/11 ...\$15.00

https://doi.org/10.1145/3363384.3363480

\begin{abstract}
Life does not begin nor end with project funding and in the case of the Commonfare project, which focuses on precariousness and how it is experienced by people in Europe, these struggles neither begin nor end with the public outcomes of the project (including devlierables, and an online platform at commonfare.net). We use Commonfare as a case study of a project at the end of research funding and the currently ongoing CIO project guides our concerns on empowerment. Both, Commonfare and CIO, are publicly funded socio-technical projects that aim to empower a group of users.
\end{abstract}

\section{EMPOWERMENT}

Tracing back to Scandinavian Participatory Design discourse, empowerment has been and continues to remain a central concern for HCI researchers. Empowering users is a common and important motive for both Commonfare ${ }^{1}$ and $\mathrm{CIO}^{2}$ projects. With the widespread adoption of ubiquitous computing [9] and technology permeating into all aspects of human life [2], addressing power relations becomes urgent, important, and inevitable. Feminist works in HCI, e.g. [1,12] alongside other efforts such as Action Research [5] and Designing for Social Justice [3] are a few examples of ongoing efforts that engage with questions concerning empowerment in HCI.

Drawing upon Foucault's notion of power, Kannabiran \& Petersen [7] highlight that "the designed system is not a passive sandbox which just permits or restricts something but is rather an active site that enables the various stakeholders to negotiate power and have a conversation" and "is the very site of contestation with inbuilt political stances, beliefs, and prejudices upon which power is constantly performed, contested and negotiated" [7]. A recent literature survey on empowerment in HCI, Schneider and colleagues [10] present a framework that seeks to understand several aspects of empowerment, although the one that interests us most is that of 'power-over' and 'power-to' relationships. Our intent, and reason for thinking about who is involved and what the output of a project is in terms, relates to these concepts of empowerment.

The CIO project is concerned with extending "human control over the technological environment by human beings, both individually and together" with an aim to "empower users to better understand and develop the technologies they use" ${ }^{2}$. In the context of CIO project, empowerment is framed as offering "new ways for people to construct and configure human physical and virtual environments, together, over time and within communities" ${ }^{2}$. Therefore, empowerment in the context of this work is concerned with what happens in the research field and lives of participants both during and after research project funding.

\footnotetext{
$\overline{{ }^{1} \text { http://pieproject.eu/ }}$

${ }^{2}$ http://cs.au.dk/research/pages/cio/
} 


\section{COMMONFARE}

Commonfare $^{1}$ was funded from mid-2016 to mid-2019, and sought to respond to approximately $25 \%$ of people living in Europe who are at risk of poverty of material deprivation, often relating to limited employment opportunities, and reducing state welfare provisions. The response took the form of a participatory design process that has involved different demographics and local communities in three pilot countries (Croatia, Italy and the Netherlands), and the development of a web-based platform commonfare.net. We understand participation in this project as including a number of different types of actors: the funding body, the project consortium members (including initially 8, but now 7 organisations: a mix of research, technical and pilot partners), and communities who are the focus of the research.

The project and its outcomes are in many ways public, for instance: it is publicly funded; the technology outcome commonfare.net is publicly visible; the software development effort is open source $^{3}$; much effort has been put into communicating achievements of the project, and related efforts by others to address precariousness in Europe via social media; and project reports and deliverables have been published on the project website. The research outputs of commonfare have strived to be published in a mix of green or gold open access.

Beyond actually writing about that which the project has done and its methods, Sciannamblo et al. [11] have sought to make public information about the process that led to the project, including a personal account and rationale of assembling the consortium of partners and the construction of the project proposal by Maurizio, a co-author of that paper and coordinator of the project. Other efforts have sought to demystify the internal organisation of the way in which the project has unfolded framed in terms of infrastructuring and organisational configurations between consortium, funding agency and research participation [8].

While the outputs publicly available now speak to work done by different consortium partners during the course of the funded portion of the project, what happens after the funding is finished? What benefit is there to people to interact with or learn from what has happened? A partner organisation was tasked with reporting on the sustainability options for the project beyond the funding term [4], which has now taken the form of the Commonfare Association ${ }^{4}$. The goals of this Commonfare Association including maintaining both the values of Commonfare and the continuity of commonfare.net, and the relationships that have been forged between different partners and communities. We now try and connect the current and future of Commonfare in terms of Empowerment, to start to unpack what the social intervention has and will mean for those it seeks to empower.

\section{COMMONFARE AND EMPOWERMENT}

Here we present initial thoughts regarding the four aspects of Schneider et al.'s [10] framework on empowerment in HCI, and while we will briefly consider all of these, we will focus more on

\footnotetext{
${ }^{3}$ github.com/Commonfare-net

${ }^{4}$ commonfare.net/en/stories/an-end-has-a-start-welcome-to-the-commonfareassociation
}

the concept of power, from which we also look beyond to Hunjan $\&$ Pettit [6].

The focus of the psychological component relates to the actual effect of empowerment, in particular, for instance, if the process of design and use of a technology serves to focus on improving selfesteem (feeling), teaching skills (knowing) or taking a particular action (doing). Schneider et al. [10] acknowledge that these are interdependent, and in the case of Commonfare, with a focus on fostering autonomy and sharing of experiences and promoting good practices there are elements of at least feeling and doing in its approach.

The persistence of empowerment relates to the temporal aspect of an intervention is of particular relevance to our concerns as it relates to an intervention or design process as having an ongoing effect beyond meaningful interaction with the Commonfare platform. Schneider et al. [10] distinguish between transient and persistent empowerment, the difference relating to whether someone is empowered only while engaging with a project, or if it persists beyond. As much of the way Commonfare has been enacted has sought to foster individual and collective autonomy and capabilities of people to confront and respond to their precarious circumstances, the intent is of course that these networks persist, and also that they are not dependent upon (although supported by) the commonfare.net platform.

The design mindset is framed in terms of the relationship between the researchers/designers and the people for whom the designed technology ultimately aims to serve. Schneider et al. [10] distinguish between expert and participatory approaches, specifically whether the designer is making the decisions, where some people, often referred to as 'users' or 'subjects' are the target, but not actively involved in the design process. As a project that takes a participatory design approach, the mindset has that has guided the interactions between the consortium partners, from different target populations and the connections with specific local good practices (e.g. businesses, social entrepreneurs, and activists that respond to issues of precariousness) has been that of including different perspectives.

Finally, the concept of power as power-to or power-over is presented by Schneider et al. [10] in terms of the relationship between actors and power. Specifically power-to refers to an actors capability, while power-over refers to an actors capability in relation to another actor (i.e. a more hierarchical relationship). For the examples provided by Schneider et al. [10] define an actor as a person or group of people, which for these concepts to be separate seems necessary, as a consideration of resources or technology as an actor in a relationship would almost always entail some level of powerover. While Schneider et al. [10] only make a distinction between two concepts of power as part of their survey of empowerment within HCI, other approaches such as Hunjan \& Pettit [6], under the category of 'expressions of power' include these plus two additional categories: power-with and power-within. Power-with is about "collective action, the ability to act together", and is about "bringing together resources and strategies". Power-within relates to a "sense of self-worth, value, dignity" [6]. A goal of Commonfare is to address issues of value and dignity, and building up people's capacities (in an individual and collective sense) to address their circumstances. We are, however, interested in how this actually 
takes place, both in the sense of the funded period of the project (mid-2016 to mid-2019), and what it means beyond this, for those who executed the project (the consortium), and those subjects who contribute to, and are the target of the design process.

\section{CONCLUSION}

Does empowerment as a concept and analytical framework to understand the goals of Commonfare provide a meaningful starting point in order to address questions of the efficacy of social good? We have provided a rather rudimentary application of an Empowerment framework to Commonfare, with more of a focus on the concept (or expression) of power, to try and connect with project goals, both within the funded period, and also to the future with regard to the Commonfare Association and $\mathrm{CIO}$ project. One aspect lacking in our initial analysis is to engage more with the content produced on the platform, as a way to try and understand if and how people are empowered by and beyond their interactions. This is a future direction of research interest, and one that becomes increasingly relevant as the Commonfare Association becomes active, as at the time of writing this association has only recently come into existence, so it is difficult to say much about how it will fare and the longevity of the project. As researchers who participate in multiple projects of such nature, defining and measuring empowerment in meaningful terms, building infrastructures for fair participation, and professional accountability while receiving public funds are important and serious issues that warrant further communal discussion in HCI.

\section{ACKNOWLEDGMENTS}

This CIO project has received funding from the European Research Council (ERC) under the European Union's Horizon 2020 research and innovation programme (grant agreement No 740548). The Commonfare project has received funding from the European Union's Horizon 2020 research and innovation programme (grant agreement No 687922).

\section{REFERENCES}

[1] Shaowen Bardzell. 2010. Feminist HCI: Taking Stock and Outlining an Agenda for Design. In Proceedings of the SIGCHI Conference on Human Factors in Computing Systems (CHI '10). ACM, New York, NY, USA, 1301-1310. https://doi.org/10. $1145 / 1753326.1753521$

[2] Susanne Bødker. 2006. When Second Wave HCI Meets Third Wave Challenges. In Proceedings of the 4th Nordic Conference on Human-computer Interaction: Changing Roles (NordiCHI '06). ACM, New York, NY, USA, 1-8. https://doi.org/10.1145/ 1182475.1182476

[3] Sarah Fox, Jill Dimond, Lilly Irani, Tad Hirsch, Michael Muller, and Shaowen Bardzell. 2017. Social Justice and Design: Power and Oppression in Collaborative Systems. In Companion of the 2017 ACM Conference on Computer Supported Cooperative Work and Social Computing (CSCW'17 Companion). ACM, New York, NY, USA, 117-122. https://doi.org/10.1145/3022198.3022201

[4] Andrea Fumagalli, Sandro Gobetti, Cristina Morini, and Rachele Serino. 2017 PIE News - Sustainability and Commonfare Report. Deliverable D5.4 produced for the PIE News project (2017). https://zenodo.org/record/3332718/files/PIE_D5.4_ FIN.pdf

[5] Gillian R. Hayes. 2011. The Relationship of Action Research to Human-computer Interaction. ACM Trans. Comput.-Hum. Interact. 18, 3, Article 15 (Aug. 2011), 20 pages. https://doi.org/10.1145/1993060.1993065

[6] Raji Hunjan and Jethro Pettit. 2011. Power: A practical guide for facilitating social change. Carnegie United Kingdom Trust Dunfermline.

[7] Gopinaath Kannabiran and Marianne Graves Petersen. 2010. Politics at the Interface: A Foucauldian Power Analysis. In Proceedings of the 6th Nordic Conference on Human-Computer Interaction: Extending Boundaries (NordiCHI '10). ACM, New York, NY, USA, 695-698. https://doi.org/10.1145/1868914.1869007
[8] Peter Lyle, Mariacristina Sciannamblo, and Maurizio Teli. 2018. Fostering Commonfare. Infrastructuring Autonomous Social Collaboration. In Proceedings of the 2018 CHI Conference on Human Factors in Computing Systems (CHI '18). ACM, New York, NY, USA, Article 452, 12 pages. https://doi.org/10.1145/3173574.3174026

[9] Yvonne Rogers. 2006. Moving on from Weiser's Vision of Calm Computing: Engaging UbiComp Experiences. In UbiComp 2006: Ubiquitous Computing, Paul Dourish and Adrian Friday (Eds.). Springer Berlin Heidelberg, Berlin, Heidelberg, 404-421.

[10] Hanna Schneider, Malin Eiband, Daniel Ullrich, and Andreas Butz. 2018. Empowerment in HCI - A Survey and Framework. In Proceedings of the 2018 CHI Conference on Human Factors in Computing Systems (CHI '18). ACM, New York, NY, USA, Article 244, 14 pages. https://doi.org/10.1145/3173574.3173818

[11] Mariacristina Sciannamblo, Peter Lyle, and Maurizio Teli. 2018. Fostering Commonfare. Entanglements between Participatory Design and Feminism. In Design Research Society 2018: Catalyst. 458-471. https://doi.org/10.21606/drs.2018.557

[12] Geeta Shroff and Matthew Kam. 2011. Towards a Design Model for Women's Empowerment in the Developing World. In Proceedings of the SIGCHI Conference on Human Factors in Computing Systems (CHI '11). ACM, New York, NY, USA, 2867-2876. https://doi.org/10.1145/1978942.1979368 